\title{
CADAP - Uma Ferramenta de apoio para um Modelo de Avaliação de Aprendizagem Baseado no Desenvolvimento de Conhecimento, Habilidades e Competências e na Reação Emocional dos Alunos
}

Carla Marina Paxiúba, UFOPA, Brasil, carla.paxiuba@ufopa.edu.br Celson Pantoja Lima, UFOPA, Brasil, celson.lima@ufopa.edu.br

\begin{abstract}
Resumo. Na atual literatura é amplamente aceito que as emoções influenciam significativamente no processo de aprendizagem, porém, como reconhecer as emoções dos alunos, e, como relacionar os vários tipos de emoções com a aprendizagem, continua a ser uma questão em aberto. Outra questão bastante estudada é como avaliar a aprendizagem dos alunos em ambientes educacionais. Para que seja possivel correlacionar as emoções dos alunos com a aprendizagem este artigo propõe utilizar a avaliação de aprendizagem baseada em evidências de desenvolvimento de habilidades e conhecimentos e competências e a utilização de uma ferramenta de reconhecimento de emoções a partir de expressões faciais dos alunos - CADAP. E assim, com estes instrumentos, obter correlações entre emoções, conteúdos didáticos, formas de ensino, estilos de aprendizagem e desempenho dos alunos.
\end{abstract}

Palavras Chave: Expressões Faciais, Emoções, Aprendizagem, Avaliação

\section{CADAP - A Support Tool for a Learning Assessment Model Based on the Development of Knowledge, Skills and Competencies and Emotional Reaction of Students}

Abstract. In the literature it is widely accepted that emotions significantly influence the learning process, but how to recognize the emotions of learners, and how to relate the various types of emotions to learning, remains an open question. Another well-studied question is how to assess students' learning in educational settings. In order to correlate students 'emotions with learning, this article proposes to use the evaluation of evidence-based learning to develop skills and knowledge and skills and the use of an emotion recognition tool from students' facial expressions - CADAP. And so, with these instruments, to obtain correlations between emotions, didactic contents, forms of teaching, learning styles and students' performance.

Keywords: Facial Expressions, Emotions, Learning, Evaluation

\section{Introdução}

A tradicional separação entre razão e emoção existente na sociedade ocidental, herdada da visão dualista de Descartes sobre a mente e corpo, contribuiu para que pouca atenção fosse dada ao papel da afetividade na aprendizagem e em outras atividades cognitivas no século passado. Porém, trabalhos de psicólogos e neurologistas têm destacado o importante papel da motivação e da afetividade em atividades cognitivas (DAMASIO, 
1996). Entende-se ainda que as emoções podem influenciar fortemente o conhecimento e os objetivos gerais dos alunos (Piaget, 1989). A conexão entre aprendizado complexo e emoções tem sido bem documentada em várias disciplinas relacionadas, como psicologia (VYGOTSKY, 1996), educação (MORA, 2013) e ciência da computação (PICARD, 1997). Mora (2013) diz que tudo o que promove a aquisição de conhecimento, como curiosidade, atenção, memória para tomada de decisão, requer a energia que conhecemos como emoção. Com objetivo de investigar as relações entre emoções e aprendizagem este trabalho é proposto. Para isto precisa definir como será feito o processo de avaliação de aprendizagem dos alunos, e o faz, se utilizando do conceito de avaliação baseado no desenvolvimento de competências.

Para que a avaliação no processo de formação possa expressar concretamente as competências desenvolvidas pelos indivíduos, é preciso que a formação e a 'avaliação por competências' sejam coerentemente planejadas em conjunto. De um modo geral, são identificados três princípios básicos da 'avaliação por competências' (HAGER, GONCZI E ATHANASOU, 1994): O primeiro refere-se à necessidade de selecionar os métodos diretamente relacionados e mais relevantes para o tipo de desempenho a avaliar, dentre os quais sugerem-se os seguintes: a) técnicas de perguntas; b) simulações; c) provas de habilidades; d) observação direta; e) evidências de aprendizagem prévia. O segundo princípio afirma que, quanto mais estreita a base de evidência, menos generalizáveis serão os resultados para o desempenho de outras tarefas. Recomenda-se, então, utilizar uma mescla de métodos que permitam a inferência da competência. Por fim, considera-se conveniente a utilização de integrados, visando a um maior grau de validez da avaliação. Sendo assim este trabalho propõe um modelo de avaliação de aprendizagem baseado em competências e investiga a correlação da aprendizagem dos alunos com a reação emocional destes. Para apoiar a identificação da reação emocional dos alunos utiliza um software para reconhecer emoções dos alunos a partir de suas expressões faciais.

Este artigo está organizado da seguinte maneira: a seção 2 apresenta o modelo de avaliação de aprendizagem e correlação com reação emocional dos alunos proposta neste trabalho, a seção 3 a ferramenta que suporta esta abordagem e a seção 4 apresenta os resultados iniciais desta proposta.

\section{Modelo de Avaliação de Aprendizagem Baseado na Reação Emocional e no Desenvolvimento de Competências, Habilidades e Conhecimento dos Alunos}

Este trabalho propõe um modelo de aprendizagem que considere a reação emocional dos alunos como parte do processo de ensino e de aprendizagem. Desta forma busca relacionar as emoções despertadas nas aulas com os resultados obtidos pelos alunos. Para isto este modelo prevê que o docente siga um processo de cinco passos apresentado na figura 1 e detalhados nas próximas subseções.

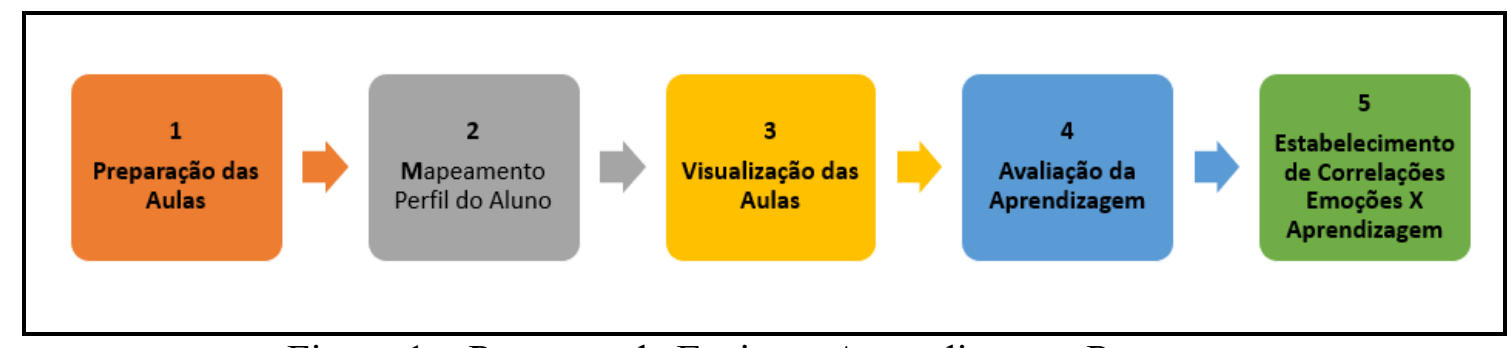

Figura 1 - Processo de Ensino e Aprendizagem Proposto 


\subsection{Etapa 1 - Preparação das Aulas}

Esta proposta prevê que o docente deve classificar as aulas quanto a abordagem de ensino utilizada - Baseada em Problemas, Baseada em Projetos, Sala de Aula Invertida, Palestra. É importante classificar corretamente as aulas em relação à abordagem, pois, é pretensão deste trabalho, avaliar a abordagem mais adequada de acordo com o perfil de aprendizado do aluno, as emoções detectadas e o desempenho dos discentes.

Para que seja possível estabelecer correlações entre as emoções dos alunos e seu desempenho, este modelo sugere realizar a avaliação de aprendizagem baseado no desenvolvimento de habilidades, competências e conhecimentos relacionados aos conteúdos apresentados em aula. Para isto ao preparar uma aula os docentes devem indicar as evidências de que o aluno desenvolveu de acordo com o esperado para os três itens: Habilidade, Competência e Conhecimento. Ao avaliar o aluno o docente irá indicar se após a aula o aluno apresenta totalmente, parcialmente ou não apresenta evidência de desenvolvimento do item esperado. A figura 2 apresenta um exemplo de como o docente deve indicar as evidências que serão utilizadas para posterior avaliação da aprendizagem dos alunos. No exemplo da figura a habilidade avaliada é a de explicar os conceitos de modelagem de banco dados. O docente avalia o desenvolvimento da habilidade em questão de acordo com a sua percepção do aluno durante as atividades avaliativas.

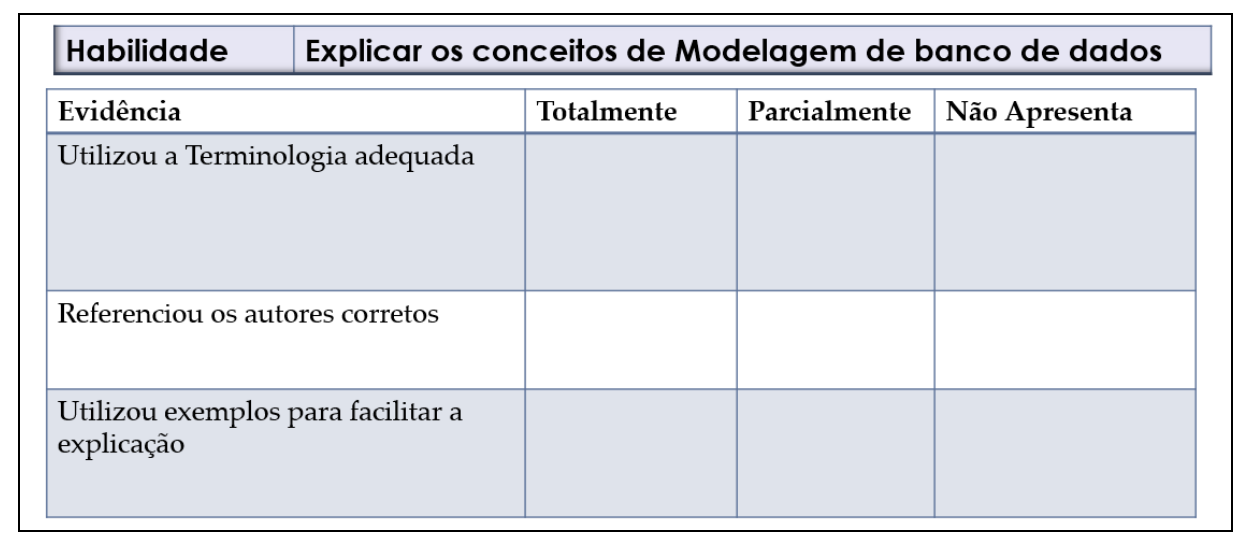

Figura 2 - Exemplo de Evidências de Habilidade

Para o registro das aulas o docente deve informar: conteúdo, tema, abordagem de ensino, forma de avaliação e evidências de desenvolvimento de habilidades, competência e conhecimento.

\subsection{Etapa 2 - Modelagem do Perfil do Estudante}

Um perfil de estudante é composto por um conjunto de propriedades que caracterizam o estudante como: sua identificação pessoal, suas características pessoais e sociais, seu perfil de aprendizagem, seu conhecimento sobre determinados assuntos, entre outros. Algumas informações relativas ao perfil do estudante, como sua identificação pessoal, preferências pessoais e sociais, são raramente modificadas. Em contrapartida, informações que envolvem aspectos cognitivos como seu estilo de aprendizagem e seu conhecimento sobre um dado assunto, podem ser alterados. Além disto, as informações sobre os aspectos cognitivos estão diretamente relacionadas ao ambiente e ao escopo de aprendizagem, fazendo com que seja necessário a ocorrência de alterações dentro deste contexto. (DOLOG ET AL, 2005). 
Uma questão fundamental dentro da área de modelagem do estudante é determinar como construir modelos concisos que representem da melhor forma os aspectos cognitivos de um aluno em relação ao ambiente em que este se encontra. Um dos pontos é identificar qual estilo de aprendizagem está associado ao estudante para que seja possível traçar o perfil de aprendizagem dele. Um estilo de aprendizagem está relacionado às estratégias que um aluno tende a aplicar com frequência a uma dada situação de ensino.

No escopo deste trabalho será adotado o modelo de Felder e Silverman (1988) para classificar os estudantes em relação a seu perfil de aprendizagem. Os autores propuseram um modelo de estilos de aprendizagem considerando métodos de ensino que pudessem atender tais estilos, e este foi o motivo da adoção deste modelo neste trabalho, por possuir uma relação entre os estilos de aprendizagem e os respectivos métodos de ensino adotados para atender tais estilos. Segundo Felder e Silverman (1988) um aluno pode ser classificado por um conjunto de estilos de aprendizagem. Isto porque cada um dos estilos descritos observa uma dimensão diferente do comportamento do aluno durante a aprendizagem. Baseado no trabalho de Felder e Silverman foi criado um instrumento chamado índice de Estilos de Aprendizagem que é utilizado para determinar as preferências em quatro dimensões (ativo/reflexivo, sensorial/intuitivo, visual/verbal e seqüêncial/global) do modelo de estilos de aprendizagem formulado por Felder e Silverman(1988). Ao

Para a modelagem do perfil do aluno, além do seu estilo de aprendizagem, serão considerados também as seguintes informações: faixa etária, sexo, grau de escolaridade e média escolar. O objetivo de realizar esta classificação na metodologia é possibilitar futuras análises que possam correlacionar o perfil do aluno, as emoções expressadas e o desempenho dos discentes nas avaliações dos conteúdos.

\subsection{Aplicação dos Conteúdos (Visualização das Aulas)}

O núcleo da abordagem proposta neste trabalho é a utilização de uma ferramenta denominada CADAP para captura e reconhecimento de emoções a partir de expressões faciais durante as aulas. Esta ferramenta possibilita analisar as emoções dos alunos e correlacioná-las com fatores como perfil de aprendizagem do aluno, dispositivos de aprendizagem utilizado pelo professor e desempenho do aluno. Para que isto seja possível durante as aulas os alunos serão filmados e a ferramenta irá capturar e analisar as expressões faciais e correlacioná-las com as sete emoções propostas por Ekman(2003) que são: nojo, tristeza, raiva, desprezo, surpresa, alegria e medo e, assim, construirá uma base de conhecimento dos alunos e de suas emoções.

\subsection{Avaliação dos Resultados}

A avaliação de aprendizagem dos alunos pode ser feita pelo docente pelo método que ele julgar conveniente: provas, projetos, seminários, porém no método que escolher deve avaliar as evidências do desenvolvimento de habilidades, conhecimentos e competências dos alunos a partir das aulas ministradas. Desta forma ao planejar sua aula o docente deve indicar as evidências do desenvolvimento dos itens e avaliar se os alunos desenvolveram completamente, parcialmente ou não desenvolveram, conforme figura 3. 


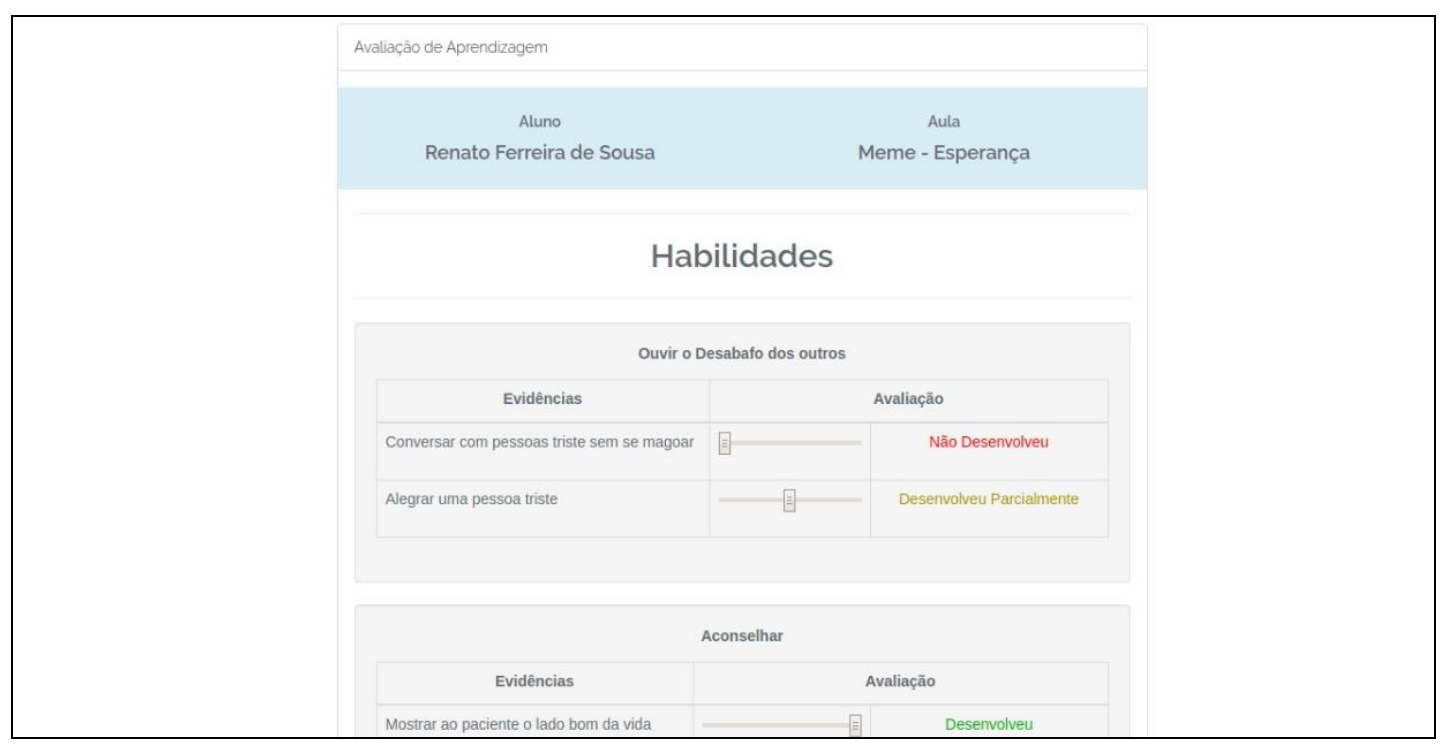

Figura 3 - Avaliação da Aprendizagem na Ferramenta CADAP

\subsection{Análise dos Resultados}

A etapa de análise dos dados é a mais importante deste processo, pois nela é feita o estabelecimento de correlações entre os elementos do processo. Para isto esta etapa irá trabalhar com cruzamento de informações dos elementos. Este cruzamento irá começar analisando informações em dois níveis, posteriormente os níveis serão incrementados conforme figura 4. As correlações de duas e três dimensões são geradas automaticamente pela ferramenta, através de relatórios e gráficos. A correlação de quatro dimensões exige análises mais detalhadas e ainda não está sendo gerada de forma automática, porém pode ser feita manualmente através da análise dos dados gerados pela ferramenta. Importante ressaltar que estas correlações irão variar de acordo com os estudantes, turmas, conteúdos e disciplinas, não sendo objetivo deste trabalho encontrar correlações universais e sim correlações para cada grupo analisado.

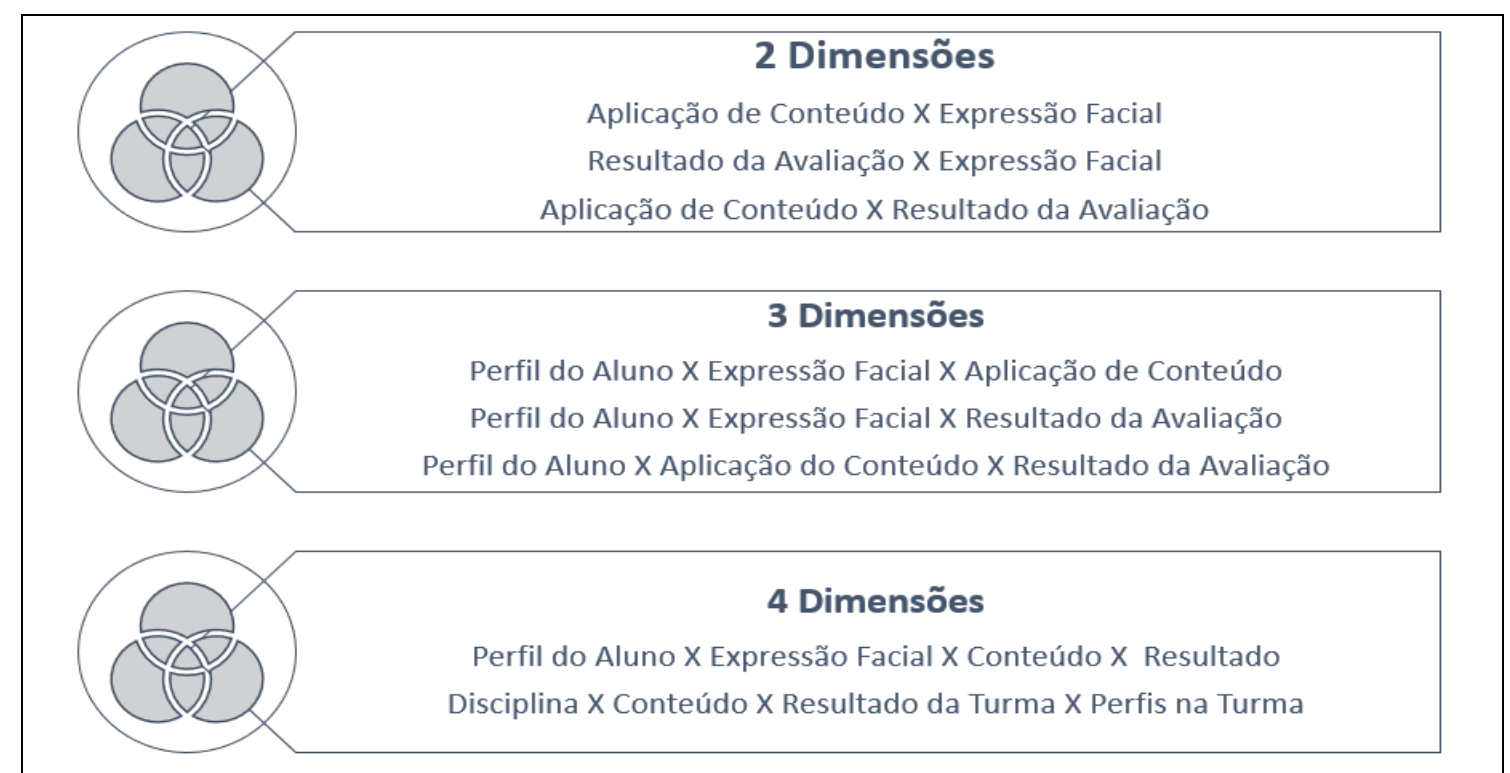

Figura 4 - Dimensões de Análise 
Estas análises possibilitarão atuar em duas frentes detalhadas a seguir.

\subsubsection{Diagnóstico}

As análises dos resultados possibilitarão realizar diagnósticos do que ocorreu conforme exemplificados abaixo:

$\bullet \%$ Percentual de alunos que permaneceram com emoções positivas/negativas

-Conteúdos que despertaram maior índice de emoções positivas/negativas

Correlações importantes entre emoções e aprendizagem poderão ser realizados a partir da análise dos dados coletados. Com estes diagnósticos os docentes poderão realizar ajustes nas suas metodologias de ensino com objetivo de melhorar a aprendizagem dos discentes.

\subsubsection{Predição de Informações}

Além da realização de diagnósticos, acredita-se que a ferramenta poderá evoluir para realizar predições, pois a partir dos dados coletados pode-se inferir informações com a aplicação de técnicas de inteligência artificial. Inferências como as citadas a seguir poderão ser realizadas:

- $\mathrm{O}$ conteúdo $\mathrm{A}$ tem $\mathrm{X} \%$ de chance de obter reações emocionais positivas da Turma

-Se o conteúdo for apresentado seguindo o modelo de ensino $\mathrm{X}$ tem maior chance de aprendizagem dos alunos

O diagnóstico e a predição de informações permitirão aos docentes uma melhor tomada de decisões relacionadas a forma de apresentação, conteúdo e real conhecimento das percepções dos seus alunos.

\section{A Ferramenta CADAP}

A ferramenta Cara de Aprender - CADAP (disponível em www.cadap.net) foi desenvolvida em um contexto que visa estudar as relações entre as emoções do aluno, os dispositivos de aprendizagem, os conteúdos utilizados e o desempenho dos alunos. Este trabalho optou por trabalhar com reconhecimento de emoções a partir das expressões faciais pois, a maioria das pesquisas foca na expressão facial. Ekman (2003) e Plutchik (2002) consideram que essa situação possa ser explicada pelo fato de justamente a face ser a região corporal humana com maiores recursos para expressão, uma vez que seus principais músculos estão concentrados na região oral, sendo também responsáveis pela mastigação, o que resulta na possibilidade de movimentação em diversas direções. Desta forma foi implementada uma ferramenta de software denominada Cara de Aprender - CADAP que segue esta abordagem.

A ferramenta CADAP permite que sejam cadastradas aulas, e, para cada aula o docente deve definir e cadastrar as evidências de competências, habilidades e conhecimentos que o aluno deve desenvolver com o conteúdo apresentado na aula. Além disso na ferramenta é possível a visualização de aulas, com a respectiva captura de expressões faciais dos alunos para reconhecimento de emoções. A ferramenta reconhece as sete emoções básicas propostas por Ekman (2003), sendo elas raiva, alegria, nojo, desprezo, surpresa, medo e tristeza. Após o aluno visualizar as aulas, o docente deve realizar as avaliações da aprendizagem do conteúdo e registrar os resultados na ferramenta, para que seja possível analisar as correlações entre as emoções dos alunos e seus resultados nas avaliações. 
$\mathrm{Na}$ figura 5 no menu superior direito é possível visualizar a imagem da face do aluno sendo capturada, enquanto este assiste aula na ferramenta. A figura 6 exibe os detalhes da análise realizada. Ao finalizar a aula a ferramenta guarda as emoções que prevaleceram nos alunos durante a visualização do conteúdo.

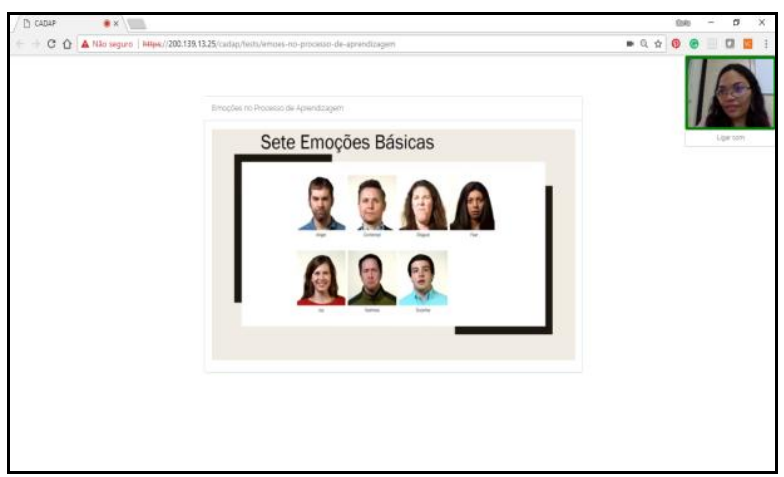

Figura 5- Visualização de Videoaulas

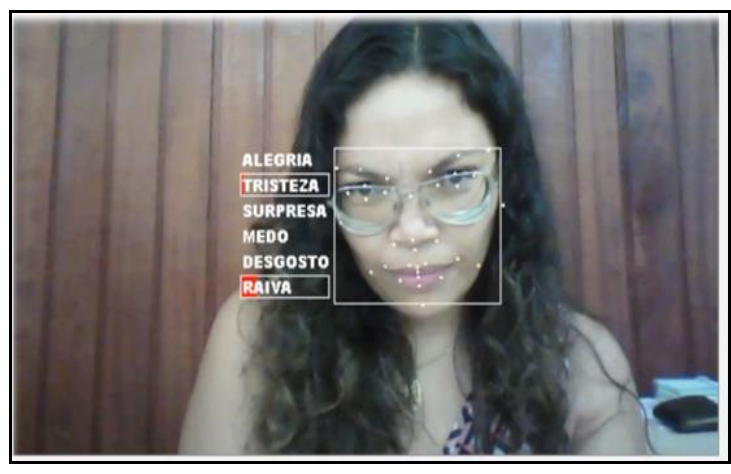

Figura 6 - Análise de Expressões Faciais

A figura 7 mostra um gráfico gerado após o aluno assistir uma videoaula no CADAP. Neste gráfico é possível acompanhar a variação das sete emoções que a ferramenta analisa. Com isso é possível verificar o momento da aula que houve variação significativa de emoções, quais emoções prevaleceram durante a aula, e posteriormente analisar se o desempenho do aluno está relacionado as emoções positivas e/ou negativas observadas no aluno durante a aula, dentre outras possíveis conclusões. As emoções variam em uma escala de 0 a 100 (zero a cem), onde zero indica que a emoção não está presente e cem indica que a emoção está no ápice. No gráfico exibido na figura 4, o eixo y apresenta esta escala de variação (0 mínimo de emoção e 100 o máximo), e o eixo x apresenta o tempo do vídeo medido em segundos. No gráfico em questão a emoção que atingiu o ápice, em tempos distintos, foi o desprezo,

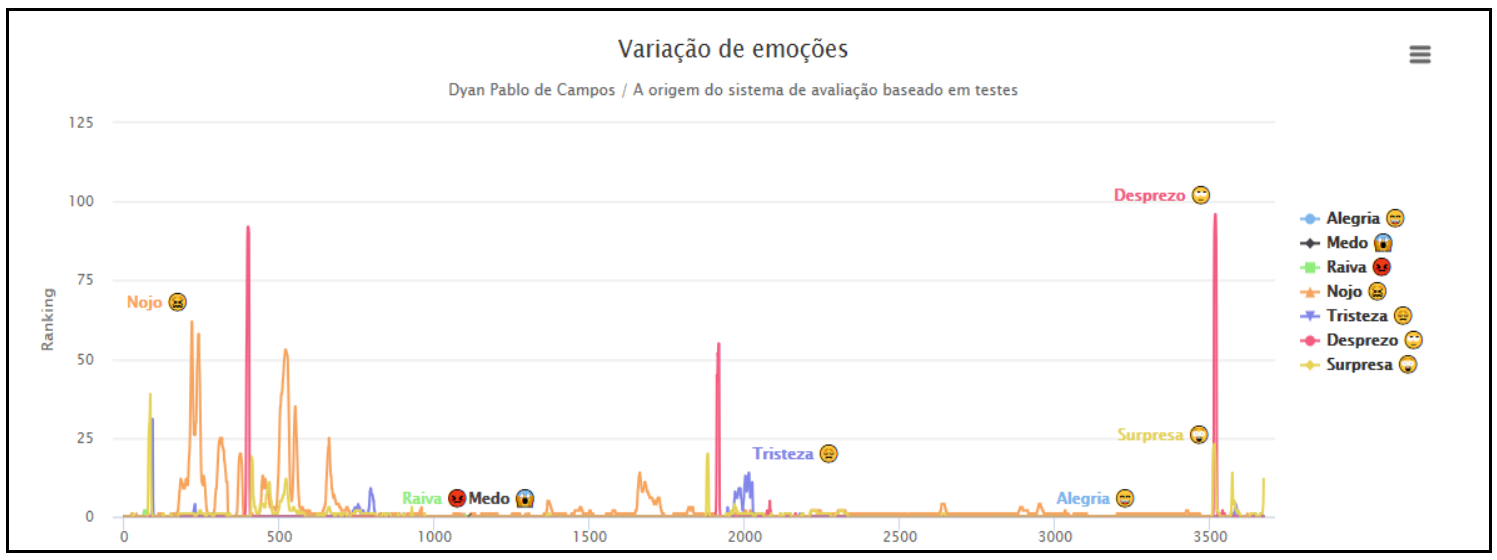

Figura 7 - Gráfico de Variação de Emoções dos Alunos

\subsection{Componente de análise de expressões faciais}

Affectiva (https://www.affectiva.com/) é uma empresa de tecnologia de medição de emoções que cresceu a partir do Media Lab do MIT(Massachusetts Institute of Technology). A Affectiva desenvolveu um software para reconhecer emoções humanas com base em pistas faciais ou respostas fisiológicas. A tecnologia desenvolvida pelo Affectiva identifica primeiro um rosto humano em tempo real ou em uma imagem ou 
vídeo. Os algoritmos de visão computacional identificam os principais pontos de referência no rosto - por exemplo, os cantos das sobrancelhas, a ponta do nariz, os cantos da sua boca. Os algoritmos de aprendizado de máquina então analisam pixels nessas regiões para classificar as expressões faciais. As combinações dessas expressões faciais são então mapeadas para as emoções. A tecnologia Affectiva mede sete métricas de emoção: raiva, desprezo, nojo, medo, alegria, tristeza e surpresa. A base de dados deste software foi treinada por mais de 7,5 milhões de faces em 87 países. Entre suas aplicações comerciais, esta tecnologia de reconhecimento de emoções é usada para ajudar as marcas a melhorar suas mensagens de publicidade e marketing. Outra aplicação importante tem sido na pesquisa política. No escopo deste trabalho a ferramenta CADAP acopla a API (Application Programming Interface) do Affectiva para reconhecimento das expressões faciais dos alunos durante as aulas e propõe uma nova aplicação para a ferramenta na área educacional. $\mathrm{O}$ segmento de educação ainda não foi explorado pelo Affectiva. Este trabalho optou por utilizar uma ferramenta consolidada para reconhecimento de expressões faciais para aumentar a confiabilidades dos resultados, e para centrar seus esforços na investigação das correlações entre emoção e aprendizagem, que é o foco desta proposta.

\section{Discussão de Resultados}

Até o momento já foram realizados vinte experimentos, que envolveram por volta de trezentos alunos e vinte docentes em algumas universidades da América Latina, onde os docentes preparam aulas e disponibilizam na ferramenta CADAP para que os alunos visualizem e suas emoções sejam monitoradas. A ferramenta captura as expressões faciais dos alunos durante a apresentação das videoaulas e ao final gera um arquivo no formato .csv com todas as capturas realizadas. As pontuações das emoções indicam quando os usuários mostram uma emoção ou expressão específica. Estas podem ser pensadas como detectores: à medida que a emoção ou expressão facial ocorre e se intensifica, a pontuação aumenta de 0 - sem expressão da emoção - para 100 - expressão da emoção totalmente presente. A figura 8 é o recorte de um arquivo gerado pela ferramenta, após o término da visualização de uma aula por um aluno.

\begin{tabular}{|r|r|r|r|r|r|r|}
\hline Alegria & Medo & Raiva & Desgosto & Tristeza & Desprezo Surpresa \\
\hline 0 & 0 & 6 & 3 & 10 & 1 & 0 \\
\hline 0 & 0 & 12 & 5 & 16 & 1 & 0 \\
\hline 0 & 0 & 10 & 6 & 15 & 1 & 0 \\
\hline 0 & 0 & 11 & 7 & 20 & 1 & 0 \\
\hline 0 & 0 & 12 & 9 & 17 & 1 & 0 \\
\hline 0 & 0 & 15 & 10 & 14 & 1 & 0 \\
\hline
\end{tabular}

Figura 8 - Recorte de um Arquivo de Captura gerado pela ferramenta

Assim com estes dados coletados é possível analisar e correlacionar as emoções dos alunos, com os conteúdos que foram apresentados a ele. Além de acompanhar a variação de emoções que ocorre durante as aulas, e saber exatamente em qual momento houve maior índice de emoções positivas ou negativas. $\mathrm{O}$ software somente armazena estas informações referentes a reações emocionais, não armazenando nenhuma filmagem dos alunos. Cabe ressaltar ainda que os alunos envolvidos nos experimentos já realizados concordaram em participar e demonstraram isso assinando um termo de consentimento disponibilizado na própria ferramenta. A figura 9 apresenta um destes experimentos, onde um grupo de alunos assiste aulas no ambiente CADAP. 


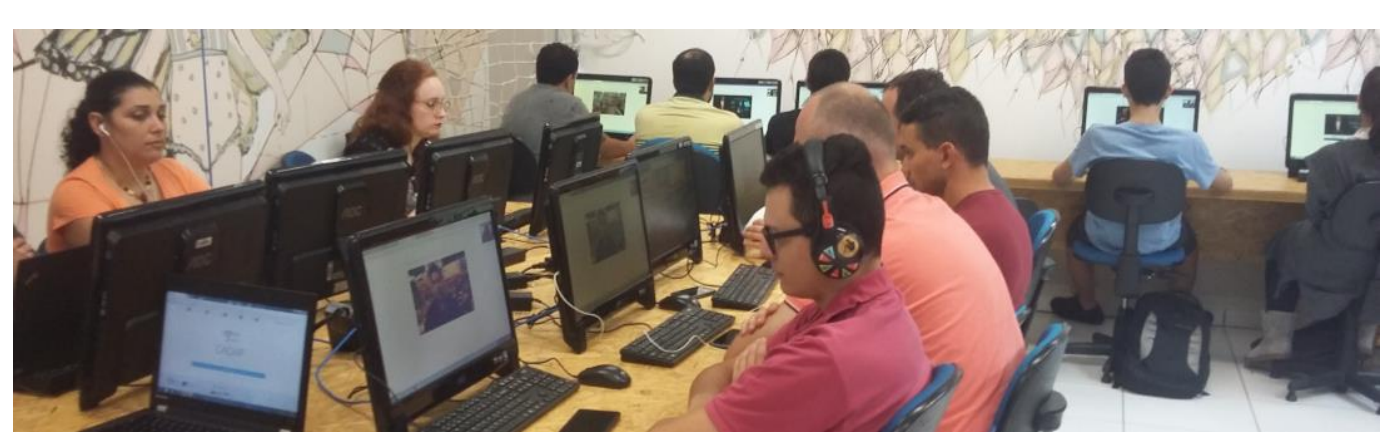

Figura 9 - Experimento em uma Turma de Ensino Superior

Com os dados gerados pela ferramenta já é possível analisar a média de emoções positivas e negativas dos alunos nas aulas e correlacionar estas informações com as avaliações realizadas sobre os assuntos tratados nas aulas. No gráfico da figura 10, o eixo y apresenta a média de variação de emoções que é medido em uma escala entre 0 e 100, porém neste caso específico, a emoção que apresentou maior média atingiu o valor 15 , e por este motivo optou-se por exibir o gráfico com uma escala entre 0 e 18 . O eixo $\mathrm{x}$ apresenta cada uma das emoções de uma determinada aluna, acompanhada em cinco aulas com temas distintos - cubismo, dadaísmo, expressionismo, futurismo e surrealismo. Ao analisar os dados representados é possível verificar que o aluno acompanhado teve desempenho mais baixo (nota menor) na aula de expressionismo onde houve predominância de emoções negativas como desprezo e nojo. Análises como essa podem ser feitas para todos os alunos que utilizarem a ferramenta. A taxa de acerto é uma informação que o docente deve fornecer de acordo com sua forma de avaliação e baseado nas evidências de desenvolvimento de competência, habilidade $\mathrm{e}$ conhecimento. Com análises como esta acredita-se que seja possível direcionar o conteúdo aos discentes de acordo com seus resultados, assim pode-se personalizar a educação dos alunos de acordo com seu desempenho e reações emocionais.

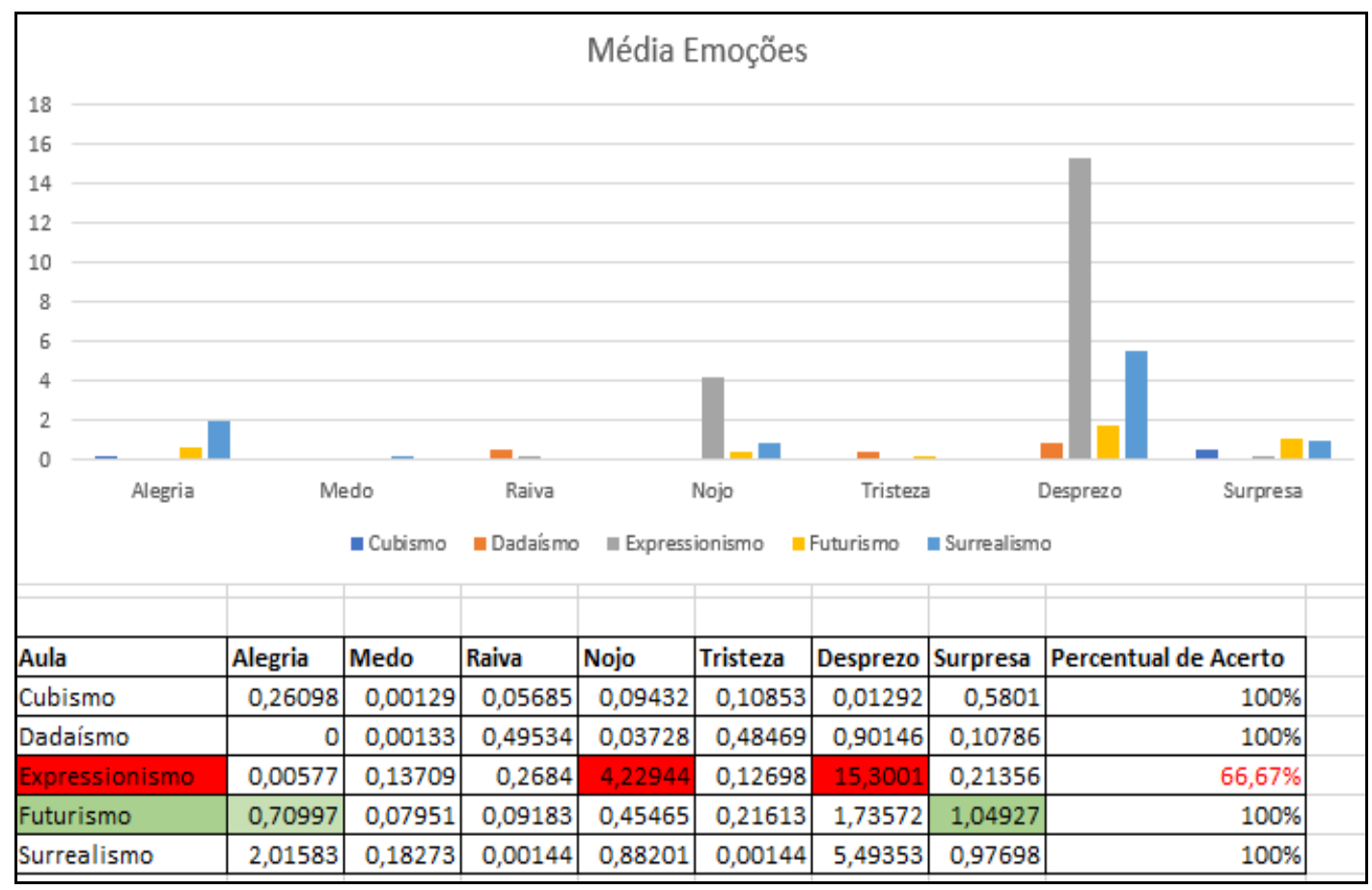

Figura 10 - Média de Emoções e Desempenho de um Aluno 


\section{Considerações Finais}

Este trabalho apresentou uma proposta de um modelo que utiliza as emoções dos alunos com objetivo de correlacioná-las com o processo de ensino e de aprendizagem. Neste modelo, as expressões faciais dos estudantes são automaticamente extraídas usando uma ferramenta de reconhecimento de expressões faciais - CADAP - ferramenta que foi desenvolvida pelos autores deste trabalho, com objetivo de ser suporte ao modelo proposto. Este modelo está sendo utilizado em diferentes Universidades e disciplinas com objetivo de analisar esta abordagem e os dados gerados pela ferramenta. Até o momento estão sendo obtidos resultados promissores que indicam a viabilidade da utilização desta proposta em ambientes de aprendizagem presenciais e a distância. Os participantes dos experimentos realizados avaliam que é possível utilizar este modelo para estabelecer correlações importantes entre emoções, conteúdos, metodologias, perfis e desempenho dos alunos. m trabalhos futuros, serão desenvolvidos algoritmos com técnicas de aprendizado de máquina para atuar também na predição de informações. Atualmente o modelo realiza diagnósticos, mas a intenção é que possa evoluir para atuar na indicação de conteúdos e metodologias baseado no histórico de reações emocionais dos alunos e respectivo desempenho e ainda na prevenção de situações de retenção e evasão escolar.

\section{Agradecimentos}

Ao Projeto ACACIA pelo apoio e suporte financeiro ao desenvolvimento deste trabalho.

\section{Referências}

DAMASIO, A. O Erro de Descartes: emoção, razão e o cérebro humano. São Paulo: Companhia das Letras, 1996.

DOLOG, P; SCHAEFER, M. A Framework for browsing manipulating and maintaining interoperable learner profiles. Proceedings of UML2005 - 10 International Conference on User Modeling, Springer Verlag, United Kingdom, 2005.

EKMAN, P. Emotions Revealed. New York: Times Book. 2003.

FELDER, R. M; SILVERMAN, L. K. Learning and Teaching Styles in Engineering Education. Engineering Education, 78, 1988.

HAGER, P.; GONCZI, A. \& ATHANASOU, J. General Issues About Assessment Of Competence. Asses. Eval.High. Educ., 19(1): 3-15, 1994.

IZARD, C. E. Emotion-cognition relationships and human development. Emotions, Cognition, and Behavior, 17-37. 1984.

MORA, F. Neuroeducación, Solo Se Puede Aprender Aquello Que Se Ama. Madri, Pp 65-72, 2013.

PIAGET, J. A Psicologia Da Criança. 17ed. Rio De Janeiro: Bertrand Brasil, 1989

PICARD, R. Affective Computing. Cambridge: Mit Press, 262 P, 1997.

PLUTCHIK, R. Emotions And Life: Perspectives From Psychology, Biology And Evolution. Washington, Dc: American Psychological Association, 2002.

VYGOTSKY, L. The problem of the environment. Em: R. Van der Veer \& J. Valsiner (Orgs.), The Vygotsky reader (pp. 338-354). Oxford, UK: Basil Blackwell Ltd, 1994 